\title{
INVESTIGATION OF PULSED MICRO-DISCHARGES AND OZONE PRODUCTION BY DIELECTRIC BARRIER DISCHARGES
}

\author{
G. M. Huang, Y. J. Zhou, M. P. Wilson, T. Wang, I. V. Timoshkin, \\ S. J. MacGregor, M. J. Given \\ Department of Electronic and Electrical Engineering, University of Strathclyde, Royal College Building \\ 204 George Street, Glasgow, UK, G1 1XW
}

\begin{abstract}
In this work, pulsed micro-discharges produced by dielectric barrier discharges (DBDs) with a sub-millimeter gap were electrically-characterized under ac voltage at $100 \mathrm{~Hz}$ and at $5 \mathrm{kHz}$. Ozone production was investigated for different discharge gap lengths and pressures. The aim of the work was to understand the statistics of filamentary current pulses and their relationship to the reduced electric field and the ozone production efficiency. A transient sinusoidal voltage of 200 cycles was employed to reduce the heating effects in the ozone-synthesis process. It was shown that the amplitude of the filamentary current pulses measured over 200 voltage cycles conformed to a Gaussian distribution. The mean filamentary current and ozone production efficiency measured at $100 \mathrm{~Hz}$ and at $5 \mathrm{kHz}$ were almost the same. The ozone production efficiency was found to increase with increasing pressure from 1 bar to $2 \mathrm{bar}$, and the gap length from $0.2 \mathrm{~mm}$ to $0.5 \mathrm{~mm}$. The maximum ozone production efficiency achieved in the work was 217 $\mathrm{g} / \mathrm{kWh}$, with a gap length of $0.5 \mathrm{~mm}, 2.0$ bar absolute pressure, and an applied voltage of $5.5 \mathrm{kV}$ at $5 \mathrm{kHz}$.
\end{abstract}

\section{I.INTRODUCTION}

Ozone is a strong oxidant and widely used in water treatment, organics degradation and in the $\mathrm{DeNO}_{\mathrm{x}}$ process. In industry, dielectric barrier discharges (DBDs) have commonly been employed as an efficient method for ozone generation, though more than $80 \%$ of the electrical energy is dissipated as heat in the discharge [1]. Optimization of pulsed micro-discharges is an important approach to increase the ozone production efficiency [2]. A considerable number of studies have been undertaken to investigate the effects of discharge gap length, dielectric barrier material, gas pressure and temperature on ozone generation efficiency, and the reduced electric field $E / N$, gas temperature and relative oxygen atom concentration were identified as the key parameters [3][8]. It was demonstrated by a number of researchers that the gas temperature rise was proportional to the discharge gap length; higher gas temperature was beneficial to the ozone decomposition process [3], [4], [7], [8]. Eliasson et al. and Kitayama et al. also reported that the ozone concentration was limited by the relative oxygen atom concentration in the discharge [3], [4]. Every oxygen atom generated by dissociation was transformed into an ozone molecule only if the relative oxygen atom concentration was less than $10^{-4}$ [3].

In order to investigate the ozone generation efficiency without considering the effects from gas temperature and relative oxygen atom concentration, dielectric barrier discharges using 200 transient voltage cycles were employed to investigate the ozone performance at different reduced electric fields, which were achieved by varying the discharge gap length and gas pressure. In addition, the pulsed filamentary current and ozone production were measured and compared at $100 \mathrm{~Hz}$ and at $5 \mathrm{kHz}$.

\section{II.EXPERIMENTAL SET-UP}

Fig. 1 shows a schematic diagram of the ozone generation and measurement systems utilized in the study. A planar DBD ozone generator with a dielectric barrier composed of soda-lime glass was designed and developed in the work. The discharge gap was accurately controlled from $0.2 \mathrm{~mm}$ to $0.6 \mathrm{~mm}$ in the experiment. The ozone generator was energized by 200 cycles of a sinusoidal voltage with amplitude of $5.5 \mathrm{kV}$ at frequencies of $100 \mathrm{~Hz}$ and $5 \mathrm{kHz}$. The ac power supply employed was a Pacific 112AMX; the output voltage of $300 \mathrm{~V}$ being stepped up to $5.5 \mathrm{kV}$ by a high-frequency transformer. Experiments were conducted in an oxygen environment with absolute pressure from 1 bar to $2 \mathrm{bar}$, and the ambient temperature of $25{ }^{\circ} \mathrm{C}$. The gas pressure inside the reactor was controlled through two needle valves, located before and after the ozone reactor. The flow rate was fixed at 0.5 $\mathrm{L} / \mathrm{min}$ in the experiment. The external current was measured through a $50 \Omega$ coaxial cable (RG405), with bandwidth of $18 \mathrm{GHz}$. The voltage across the ozone reactor was measured using a LeCroy PPE6kV highvoltage probe $(400 \mathrm{MHz})$. Measurement data were acquired by an oscilloscope (WaveRunner $625 \mathrm{Zi}$ ) with a bandwidth of $2.5 \mathrm{GHz}$ and a maximum sampling rate of $40 \mathrm{GS} / \mathrm{s}$. 


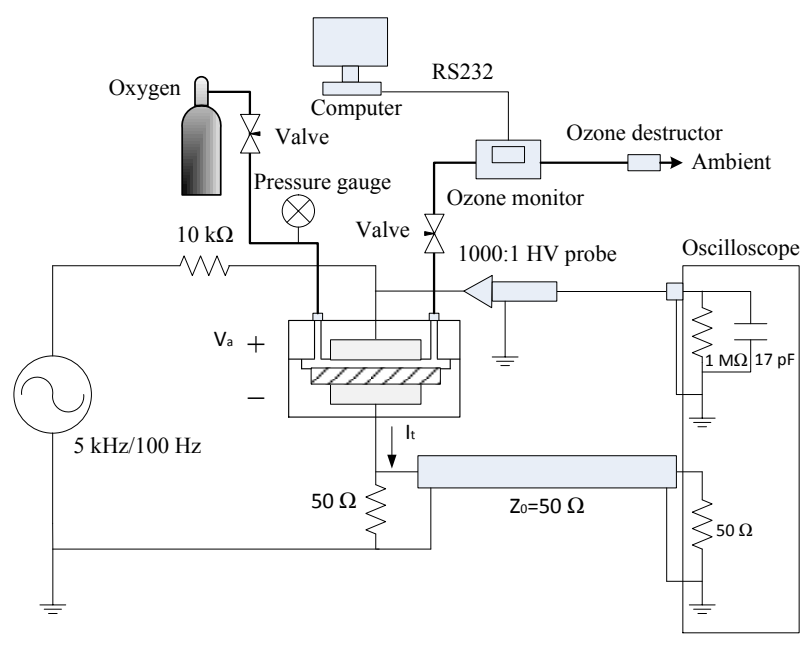

Figure 1. Schematic diagram of experimental set-up.

The ozone concentration was measured using an ozone monitor (BMT964) and the measurement data was transferred to a computer for real-time integration, to calculate the total ozone production during the application of 200 voltage cycles. The discharge power was determined by integration of the instantaneous product of the digitized voltage and current signals from the oscilloscope. The breakdown voltage was determined through the Lissajous figure, measured separately using a 220-nF measuring capacitor.

\section{III.RESULTS AND DISCUSSION}

\section{A. Filamentary Current Pulse Statistics}

Fig. 2 shows the voltage and current waveforms measured at $100 \mathrm{~Hz}$ and at $5 \mathrm{kHz}$. It shows that the impulsive current started to appear before the voltage crossed zero and finished before the maximum voltage. The current pulse measured in the external circuit was induced by the micro-discharge in the gap. The microdischarge was quenched due to the reversed internal electric field created by the accumulated charge on the dielectric barrier. The electric field in the gap space will be affected by the reversed electric field, and reduces depending upon the location and the distance to the micro-discharge. With increasing supply voltage, the electric field in the gap will recover until it is high enough to initiate a new micro-discharge at another location. When the voltage is near the maximum, the electric field in the gap can't recover to the breakdown level to initiate a new micro-discharge. Fig. 2 shows the similarity in the voltage and current waveforms measured at $100 \mathrm{~Hz}$ and at $5 \mathrm{kHz}$, excepting the higher displacement current at 5 $\mathrm{kHz}$.
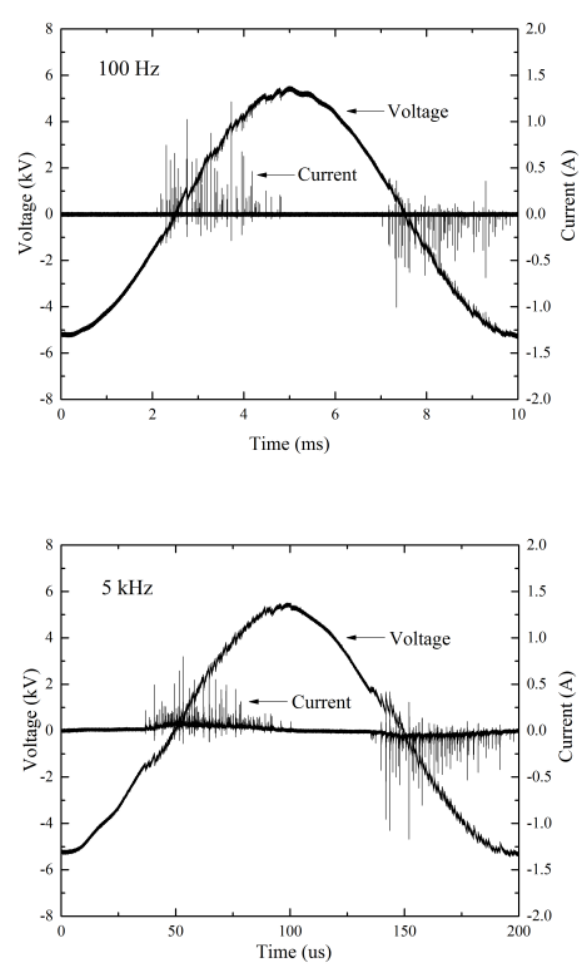

Figure 2. Voltage and current waveforms at $100 \mathrm{~Hz}$ and at $5 \mathrm{kHz}$.
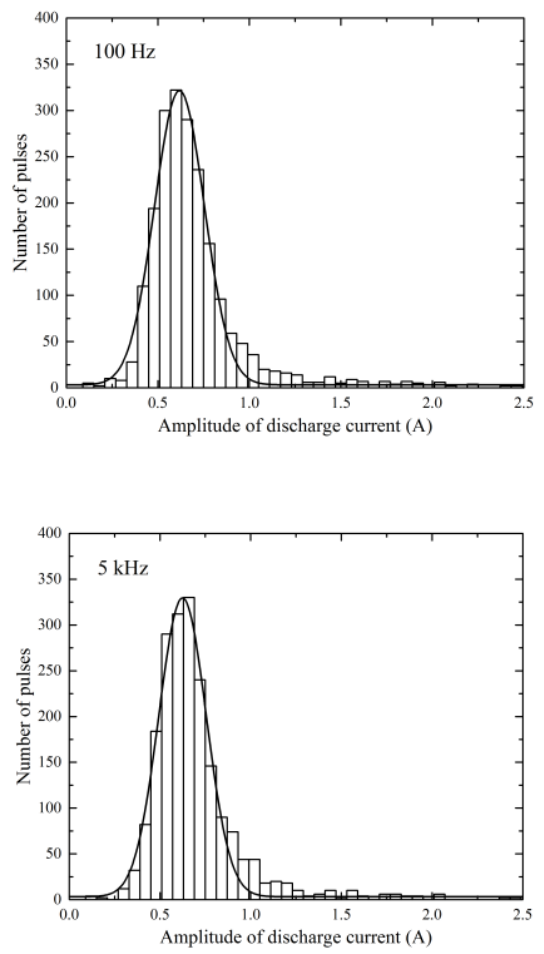

Figure 3. Distributions of filamentary current amplitude at $100 \mathrm{~Hz}$ and at $5 \mathrm{kHz}$. 
The filamentary current $I_{f}$ in the discharge gap was calculated using Eq. (1) [9]:

$$
I_{f}=\left(1+\frac{C_{g}}{C_{d}}\right) I_{t}-C_{g} \frac{d V_{a}}{d t}
$$

In Eq. (1), $I_{t}$ is the total current measured in the external circuit, $V_{a}$ is the voltage applied across the reactor, $C_{g}$ is the capacitance of the gap and $C_{d}$ is the capacitance of the dielectric barrier. The amplitudes of the filamentary currents over the 200 voltage cycles were acquired at 100 $\mathrm{Hz}$ and at $5 \mathrm{kHz}$, and their distributions are shown in Fig. 3. It can be seen that the amplitude of the filamentary current pulses in barrier discharges conforms to a Gaussian distribution. The mean value of the amplitude of the filamentary currents and the standard deviation at both frequencies were almost the same, with the values listed in Table 1.

\section{B. Ozone Production Efficiency}

The concentration of ozone generated by 200 voltage cycles was monitored by an ozone analyzer in real time. Fig. 4 shows the change in ozone concentration with time at frequencies of $100 \mathrm{~Hz}$ and $5 \mathrm{kHz}$. It can be seen that the ozone concentration at $100 \mathrm{~Hz}$ increased to its peak value at a slightly slower rate than that at $5 \mathrm{kHz}$, but the integrated ozone production levels at the different frequencies are equal. The power consumption, estimated through a Lissajous figure (Fig. 5) also translates to similar energy consumption at both frequencies. All of the calculated performance parameters at $100 \mathrm{~Hz}$ and at 5 $\mathrm{kHz}$ are shown in Table 1.

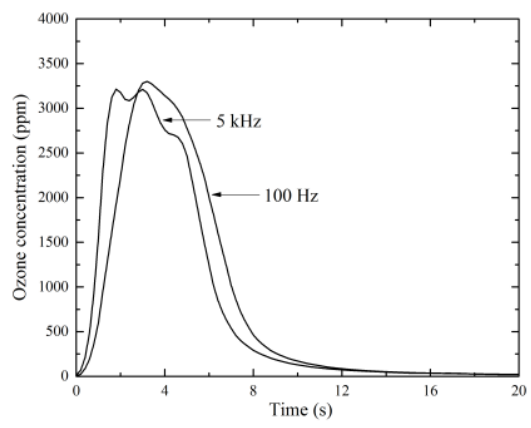

Figure 4. Ozone concentration curves at frequencies of $100 \mathrm{~Hz}$ and $5 \mathrm{kHz}$.

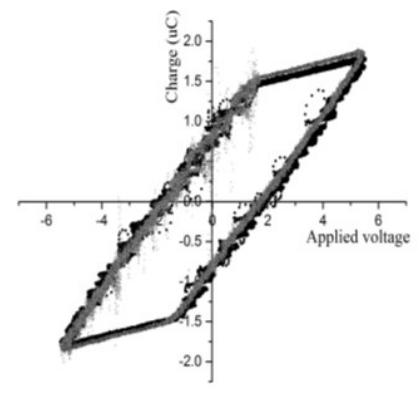

Figure 5. Lissajous figure at both $100 \mathrm{~Hz}$ and $5 \mathrm{kHz}$.
Table 1. Parameters at both $100 \mathrm{~Hz}$ and $5 \mathrm{kHz}$.

\begin{tabular}{|c|c|c|c|c|}
\hline \multirow{2}{*}{ Frequency $(\mathrm{Hz})$} & \multicolumn{2}{|c|}{$\begin{array}{c}\text { Amplitude of } \\
\text { filamentary } \\
\text { current }\end{array}$} & \multirow{2}{*}{$\begin{array}{c}\text { Energy } \\
\text { consumption } \\
\text { (J) }\end{array}$} & \multirow{2}{*}{$\begin{array}{c}\text { Ozone } \\
\text { production } \\
\text { efficiency } \\
(\mathrm{g} / \mathrm{kWh})\end{array}$} \\
\hline & $\begin{array}{l}\text { Mean } \\
\text { value } \\
\text { (A) }\end{array}$ & $\begin{array}{l}\text { Standard } \\
\text { deviation } \\
\text { (A) }\end{array}$ & & \\
\hline $100 \mathrm{~Hz}$ & 0.624 & 0.02 & 2.275 & 167.8 \\
\hline $5 \mathrm{kHz}$ & 0.618 & 0.02 & 2.282 & 165.3 \\
\hline
\end{tabular}

\section{Effects of Gap Length and Gas Pressure}

Fig. 6 shows that ozone generation efficiency increased with increasing gap length from $0.2 \mathrm{~mm}$ to $0.5 \mathrm{~mm}$ and then saturated, with the highest ozone efficiency obtained being $166 \mathrm{~g} / \mathrm{kWh}$. It has been reported by a number of researchers that smaller gap length can result in better heat removal, which leads to increased ozone concentration and generation efficiency [4], [8]. In the present work, however, due to the application of 200 voltage cycles only, the heating effect in the reactor can be neglected. The breakdown voltage changes with the gap length according to Paschen's law. The reduced electric field $E / N$ will vary with different gap lengths. From the Fig. 7, it shows that the reduced electric field decreases from $185 \mathrm{Td}$ to $130 \mathrm{Td}$ when the gap length increases from $0.2 \mathrm{~mm}$ to $0.6 \mathrm{~mm}$. The highest ozone generation efficiency was achieved when $E / N=140 \mathrm{Td}$.

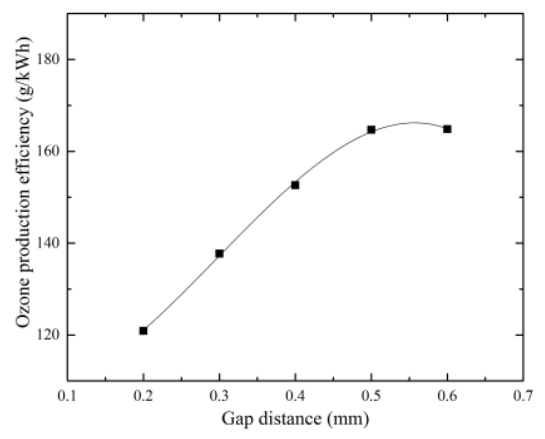

Figure 6. Ozone generation efficiency with different gap lengths at $1 \mathrm{bar}$, under applied voltage of $5.5 \mathrm{kV}$ at $5 \mathrm{kHz}$.

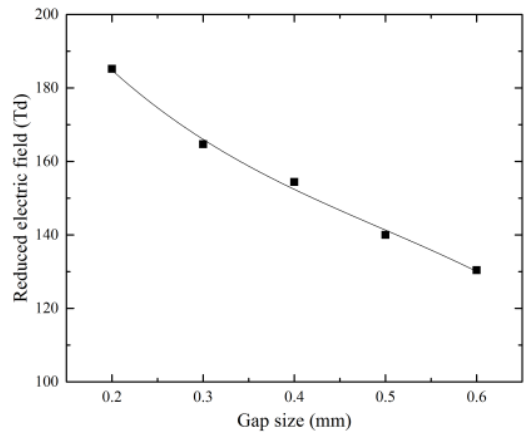

Figure 7. The dependence of $E / N$ on gap length. 
Fig. 8 shows the dependence of ozone generation efficiency on the gas pressure. It demonstrates that the ozone efficiency increases with increasing gas pressure. The highest ozone production efficiency of $217 \mathrm{~g} / \mathrm{kWh}$ was achieved at the highest tested pressure of 2 bar absolute. The reduced electric fields at different pressures were calculated and plotted in Fig. 9, which shows that the value of $E / N$ decreases slightly with increasing pressure. The $E / N$ magnitude was reduced by $4 \%$ when the absolute pressure was increased from 1.2 bar to 2 bar. The highest ozone generation efficiency was obtained at the lowest $E / N$ of $126 \mathrm{Td}$.

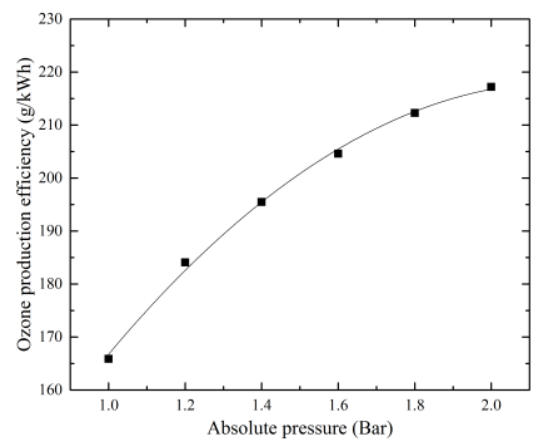

Figure 8. Ozone generation efficiency with different pressures at $0.5 \mathrm{~mm}, 5.5 \mathrm{kV}$ and $5 \mathrm{kHz}$.

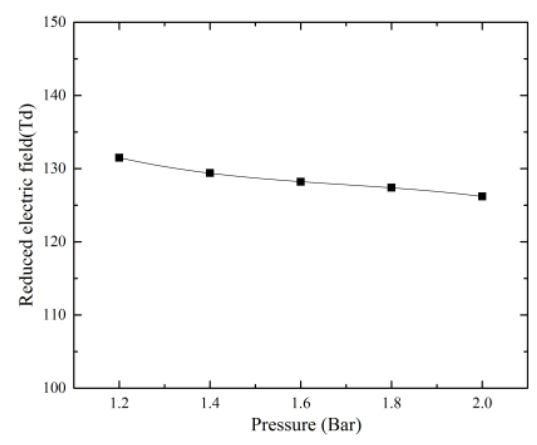

Figure 9. The dependence of $E / N$ on gas pressures.

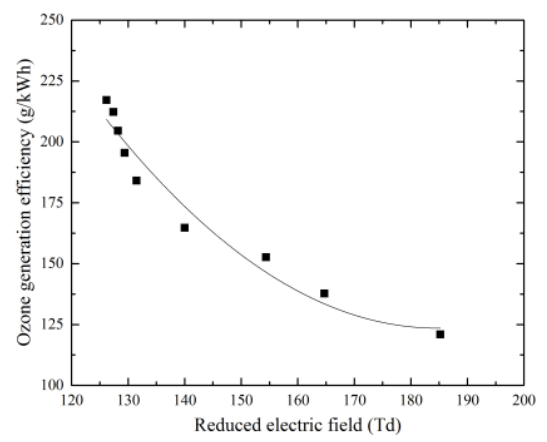

Figure 10. Ozone generation efficiency at different $E / N$
Fig. 10 shows the dependence of ozone generation efficiency on $E / N$. It can be seen that the ozone generation efficiency decreases with an increase of $E / N$ in the range from $126 \mathrm{Td}$ to $185 \mathrm{Td}$. This result is in agreement with the findings of Kitayama et al, who reported that the maximum ozone yield decreases gradually with increasing value of the reduced electric field strength, when $E / N>100$ Td [4].

\section{CONCLUSION}

A transient sinusoidal voltage of 200 cycles was employed to investigate the statistics of filamentary current pulses and the ozone generation efficiency under different experimental conditions. The amplitude of the filamentary discharge currents in dielectric barrier discharges conformed to a Gaussian distribution. The mean filamentary current and ozone generation efficiency measured at $100 \mathrm{~Hz}$ and at $5 \mathrm{kHz}$ were almost the same. The highest ozone generation efficiency of $217 \mathrm{~g} / \mathrm{kWh}$ occurred when $E / N$ was $126 \mathrm{Td}$. The ozone generation efficiency decreased with an increase of $E / N$ in the range from $126 \mathrm{Td}$ to $185 \mathrm{Td}$.

\section{V.REFERENCES}

[1] S. Jodzis and J. Petryk, "Gas temperature in an ozonizer. The computer modeling of an actual discharge system," IEEE Trans. Plasma Science. Vol. 39. No. 11, pp. 2020-2021, Nov. 2011.

[2] U. Kogelschatz, B. Eliasson and W. Egli, "Dielectricbarrier discharges principle and applications," Journal de Physique IV (Colloque), vol. 7, pp.47-66, 1997.

[3] B. Eliasson, M. Hirth and U. Kogelschatz, "Ozone synthesis from oxygen in dielectric barrier discharges," J. Phys. D: Appl. Phys. 20, pp. 1421-1437.

[4] J. Kitayama and M. Kuzumoto, "Theoretical and experimental study on ozone generation characteristics of an oxygen-fed ozone generator in silent discharge," J. Phys. D: Appl. Phys. 30, pp. 2453-2461, 1997.

[5] Y. Sung and Tatsuya Sakoda, "Optimum conditions for ozone formation in a micro dielectric barrier discharge," Surface \& Coatings Technology, No.197, pp. 148-153, 2005.

[6] A. A. Garamoon, F. F. Elakshar, A. M. Nossair and E. F. Kotp, "Experimental study of ozone synthesis," Plasma Sources Sci. Technol. No. 11, pp. 254-259, 2002.

[7] S. Jodzis, "Temperature effects under ozone synthesis process condition,” Eur. Phys. J. Appl. Phys. No. 61, p. 24319, 2014.

[8] Yagi S and Tanaka, "Mechanism of ozone generation in air-fed ozonisers," J. Phys. D: Appl. Phys. No. 12. pp. 1509-1520,1979.

[9] M. Raether, Electron avalanches and breakdown in gases, Butterworths, London, 1964. 